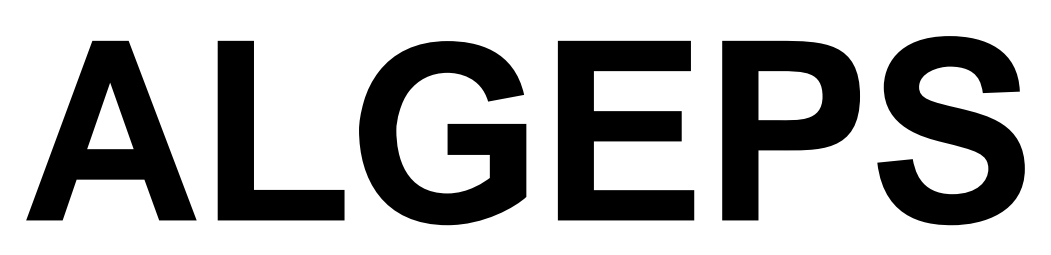

REVISTA DE GEOLOGIA, SÈRIE B no 588 - Abril del 2012

ISSN $1132-7014$

D.L.B. 28.178 - 92

12 pàgines

\title{
RECORRIDO DESDE LECINA A BARCABO Y A BOLTAÑA, A TRAVÉS DEL PATRIMONIO GEOLÓGICO Y MINERO DE LA COMARCA DEL SOBRARBE
}

Josep M. Mata-Perelló

Aquest recorregut va ésser experimentat amb docents el dia 12 DE JUNY DEL 2010 


\section{RECORRIDO DESDE LECINA A BARCABO Y A BOLTAÑA, A TRAVÉS DEL PATRIMONIO GEOLÓGICO Y MINERO DE LA COMARCA DEL SOBRARBE}

\section{ADVERTENCIAS PREVIAS}

Como en otros recorridos de RECONOCIMIENTO GEOLÓGICO (o de RECONOCIMIENTO GEOLÓGICO Y MINERO), el recorrido se compondrá de diversas PARADAS.

Por otra parte, habrá que tener en cuenta, en todo momento, (especialmente antes de empezar los recorridos de los diferentes tramos), el estado de los caminos y carreteras, por donde transitará el recorrido.

Finalmente, como ya hacemos en otros recorridos similares, queremos decir que hace falta tener un cuidado muy especial en el respeto a la naturaleza, a lo largo de todo el recorrido del itinerario, y también fuera de él.

\section{BREVE INTRODUCCIÓN GEOLÓGICA}

Todo el recorrido de este itinerario, se desarrollará por distintas zonas ocupadas por el Sistema Pirenaico (o simplemente por los Pirineos). Concretamente, en todo el recorrido se circulará por el denominado Surpirineo Central.

Así, el recorrido se iniciará en las cercanías de Naval, dentro del denominado Surpirineo Central, por los denominados Pirineos Meridionales (también a menudo conocidos como Prepirineo Meridional). Luego, siempre dentro de esta unidad geológica, se irá circulando hasta Lecina, en la parte septentrional de la Sierra de Guara hasta Boltaña, en donde finalizará el recorrido.

\section{BREVE INTRODUCCIÓN GEOGRÁFICA}

El recorrido del presente itinerario se efectuará exclusivamente por una comarca aragonesa, por la del Sobrarbe. Así se iniciará en Lecina, para ir luego hacía Barcabo y Boltaña, en donde finalizará.

Por otro lado, la totalidad del recorrido transitará dentro de la cuenca del río Cinca y de sus afluentes. 


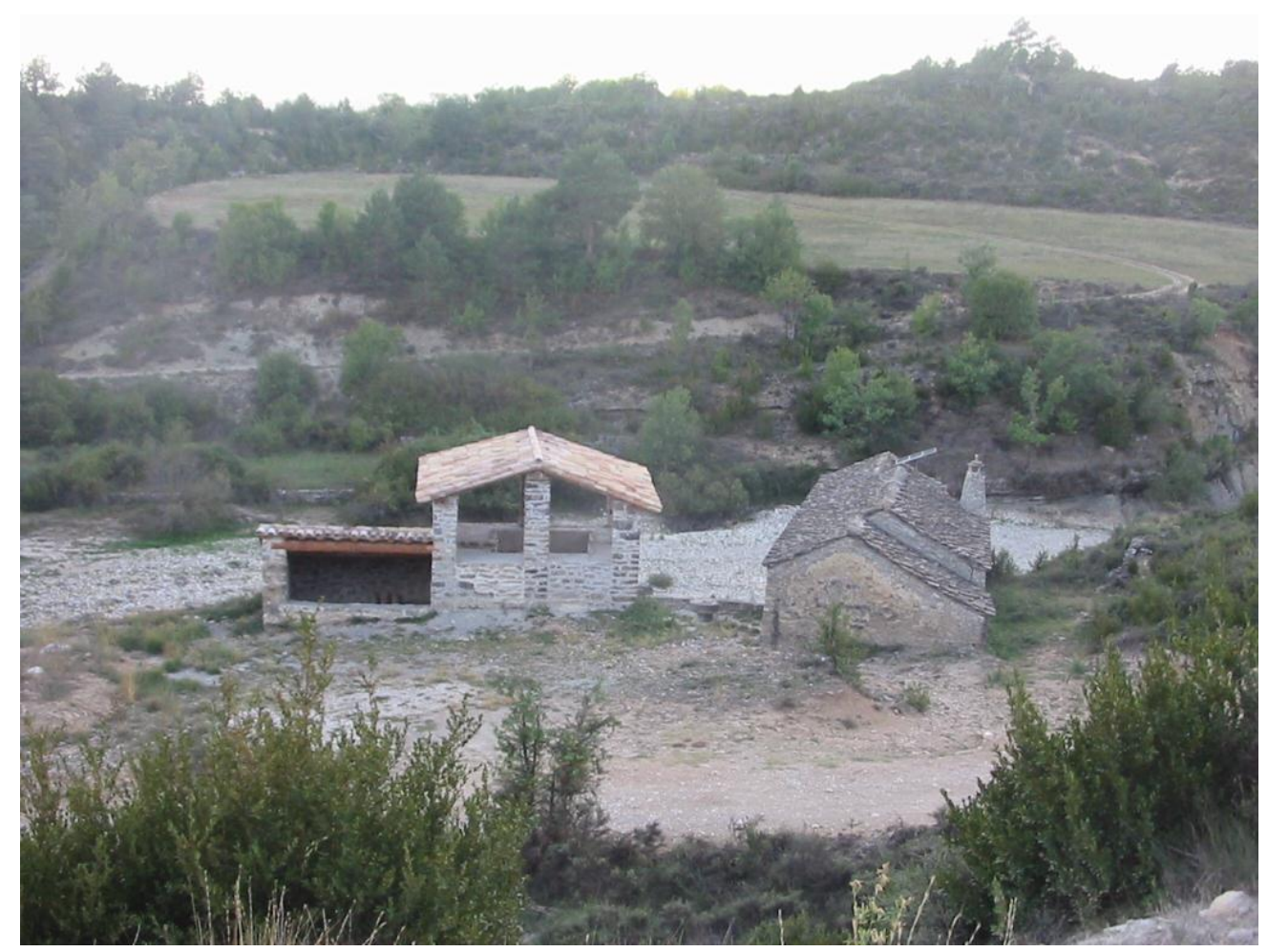

Almazorre (Barcabo): la tejera y la almazara

\section{OBJETIVOS GENERALES DE ESTE ITINERARIO}

En este itinerario, los objetivos generales que se han de conseguir, se pueden concretar en los siguientes aspectos:

1.- Estudio y reconocimiento de los materiales mesozoicos y cenozoicos situados en el Surpirineo Central. Estos materiales los iremos encontrando a lo largo de todo el recorrido del itinerario.

2.- Estudio y reconocimiento de las estructuras del Surpirineo Central, a lo largo de todo el recorrido del itinerario.

3.- Visión de algunas de las antiguas explotaciones encontradas a lo largo del recorrido del itinerario.

4.- Visión de los diferentes lugares directamente relacionados con el Patrimonio Geológico que iremos encontrando a lo largo del recorrido de este itinerario.

5.- Visión de los diferentes lugares directamente relacionados con el Patrimonio Minero que veremos a lo largo del recorrido de este itinerario. Dentro de él cabe mencionar el relacionado con la Tejera de Almazorre (en Almazorre, Barcabo) (Sobrarbe), entre otros lugares, 


\section{ANTECEDENTES BIBLIOGRÁFICOS}

En relación con este itinerario, no conocemos ningún antecedente, de otro autor relativo a otro itinerario que discurra por este lugar. En este sentido va a ser una primicia en todos los aspectos.

Por otra parte, haremos mención de algunos trabajos, de carácter geológico generalista, que corresponden a los trabajos del IGME (1972, 1974 y 1975), relativos al Mapa Geológico de España (a Escala 1.200.000), al Mapa Metalogenético de España y al Mapa de Rocas Industriales de España.

Con respecto a las mineralizaciones que iremos encontrando, mencionaremos los trabajos de: CALVO et altri (1988); MAESTRE (1845); así como nuestros trabajos: MATA-PERELLÓ (1987 y 1992).

También mencionaremos el trabajo de PRAMES (2005) dedicado a la comarca del Sobrarbe. Así como el del GOBIERNO DE ARAGÓN (2001), dedicado a los Puntos de Interés Geológico de Aragón.

Finalmente, diremos que todos estos trabajos (así como otros que ahora no hemos aludido), figurarán mencionados, por orden alfabético, en el apartado dedicado a las REFERENCIAS BIBLIOGRÁFICAS.

\section{RECORRIDO DEL ITINERARIO}

Este recorrido se iniciará en las inmediaciones de la población de Lecina (del municipio de Barcabo), por donde se efectuará la primera parada del itinerario, muy cerca del límite comarcal.

Luego, el recorrido se dirigirá hacía la población de Barcabo, en donde se realizaran varias paradas, una de ellas en las inmediaciones de Almazorre, una de las poblaciones agregadas de este municipio. Antes se habrá pasado por Hospitaled.

Tras ello, el recorrido continuará hacía el Norte, pasando por las cercanías de Eripol y llegando luego a Arcusa. En este tramo se realizará una nueva parada. Luego, continuando siempre hacía el Norte, el recorrido pasará cerca de Urdiales, por donde se realizará una nueva parada.

Seguidamente, el recorrido transcurrirá por Latorrecilla y más adelante por Bestreguin. Tras ello, se llegara a las cercanías de la población de Margudgued. En todo este tramo no se efectuará ninguna parada.

Finalmente., el recorrido llegará hasta la población de Boltaña. Ahí se realizará la última parada del itinerario, finalizando aquí el recorrido. 


\section{DESCRIPCIÓN DEL ITINERARIO}

Como de costumbre, haremos una serio de PARADAS (o ESTACIONES), en donde se realizaran diversas explicaciones en torno a las características del lugar en donde se halla la PARADA.

Por otra parte, en ellas haremos mención del término municipal dónde se encuentran, así como del número del "Mapa Topográfico Nacional (a escala 1:50.000, que indicaremos entre paréntesis. Así, ahora (en este recorrido) utilizaremos solamente las hojas: 211 (o de Boltaña) y $\mathbf{2 4 9}$ (o de Alquezar).

Así, la relación ordenada de las paradas que constituyen el recorrido de este itinerario, es la siguiente:

PARADA 1. TEJAR DE LECINA, (Lecina, término municipal de Barcabo, comarca del Sobrarbe). (Hoja 249).

El recorrido del presente itinerario, cabe realizarlo en este lugar. Este tejar se halla situado en las inmediaciones de Lecina, a menos de $1 \mathrm{Km}$ al SSE del pueblo. Se accede directamente desde el pueblo por un sendero.

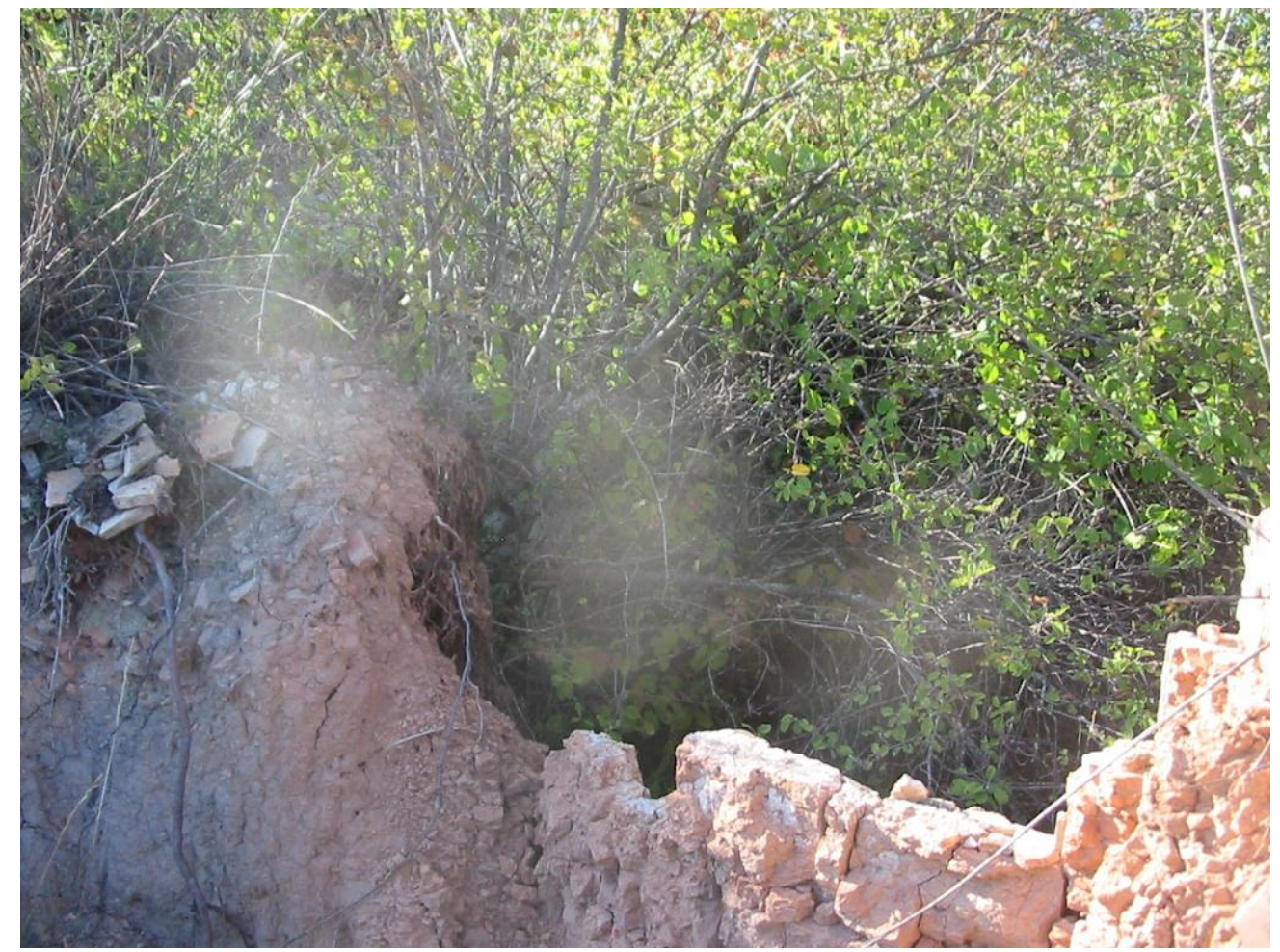

Restos del tejar

Este lugar, así como todo el recorrido efectuado, se halla situado en pleno Surpirineo Central, por los denominados Pirineos Meridionales (también a menudo conocidos como Prepirineo Meridional).Así, por doquier se hallan afloramientos de los materiales mesozoicos, generalmente del Cretácico. 
En este lugar hay los restos de un antiguo tejar (el Tejar de Lecina). No se hallan en buen estado de conservación, conservándose los restos del horno. A pesar de su mal estado de conservación, este tejar forma parte del Patrimonio Minero del Sobrarbe.

Asimismo, junto al tejar se observan una antigua explotación de materiales arcillosos. Los materiales extraídos constituían la materia prima para el tejar.

PARADA 2. TEJAR DE BARCABO, (término municipal de Barcabo comarca del Sobrarbe). (Hoja 249).

Después de realizar la parada anterior, cabe retornar a Lecina. Luego será necesario ir hacía la población de Barcabo (la capital del municipio). Al llegar al pueblo, convendrá hacer una hijuela, así seguiremos por camino - carretero de Naval. A menos de $1 \mathrm{Km}$ del pueblo, hacía el SE encontraremos el tejar. Ahí haremos una parada, a unos 7 $8 \mathrm{Km}$ de la anterior.

A lo largo de todo este recorrido habremos ido encontrando afloramientos de los materiales mesozoicos citados en la parada anterior. En efecto, estos son también los que afloran en este lugar.

Aquí, hay los restos de un antiguo tejar. Éste no se halla en buen estado de conservación; aunque el horno se halla en relativo estado. Como el anterior, forma parte del Patrimonio Minero del Sobrarbe.

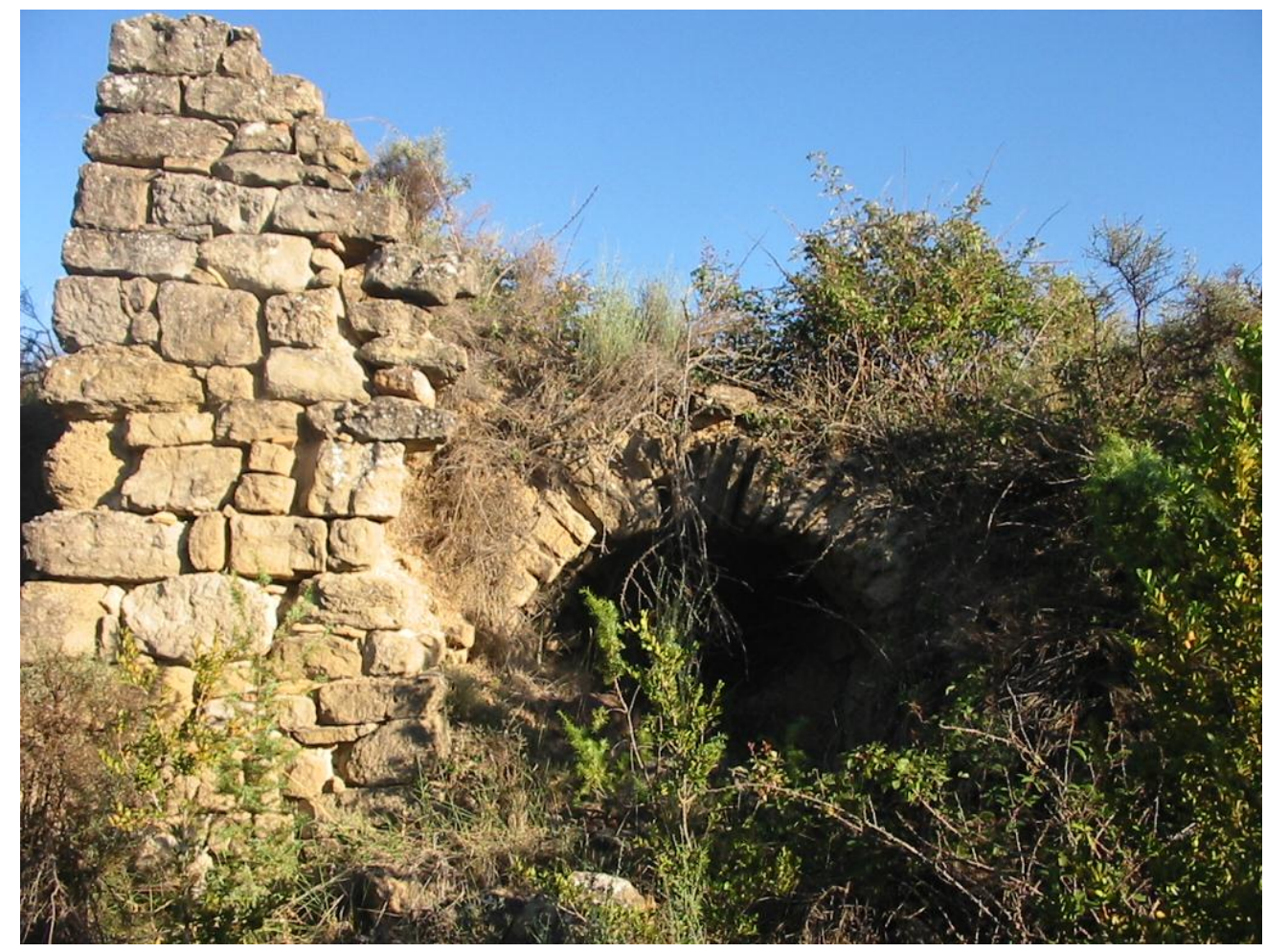

Restos del Tejar de Barcabo 
PARADA 3. TEJAR DE ALMAZORRE, (Almazorre, término municipal de Barcabo, comarca del Sobrarbe). (Hoja 249).

Desde la parada anterior, es necesario retornar al pueblo de Barcabo, finalizando así la hijuela. Luego, será necesario continuar por la carretera que conduce hacía Boltaña. Así, pronto se pasará por las inmediaciones de Hospitaled, por la derecha. Poco después, por la izquierda, se encontrará el camino del Tejar de Almazorre. Ahí se llegará fácilmente, siguiendo las indicaciones. Al llegar al tejar y a la almazarra, se efectuará una nueva parada, a unos $4 \mathrm{Km}$ de la parada anterior.

En este recorrido habremos ido encontrando afloramientos de los materiales mesozoicos citados en las paradas anteriores. Estos materiales se hallan situados en pleno Surpirineo Central, en los denominados Pirineos Meridionales (también a menudo conocidos como Prepirineo Meridional). Así, por doquier se hallan afloramientos de los materiales mesozoicos, generalmente del Cretácico.

En este lugar hay un antiguo tejar (Tejar de Alnazorre). Éste ha sido recientemente restaurado, conservando su esbeltez. Forma parte, como los anteriores, del Patrimonio Minero del Sobrarbe. Asimismo, en las cercanía del tejar, pueden verse las algunas de las antiguas explotaciones arcillosas que proporcionaban materia prima para el funcionamiento del tejar.

Por otra parte, junto al tejar, se ha recuperado también una interesante almazarra (o molino de aceite). Este lugar da, precisamente, el nombre al pueblo.

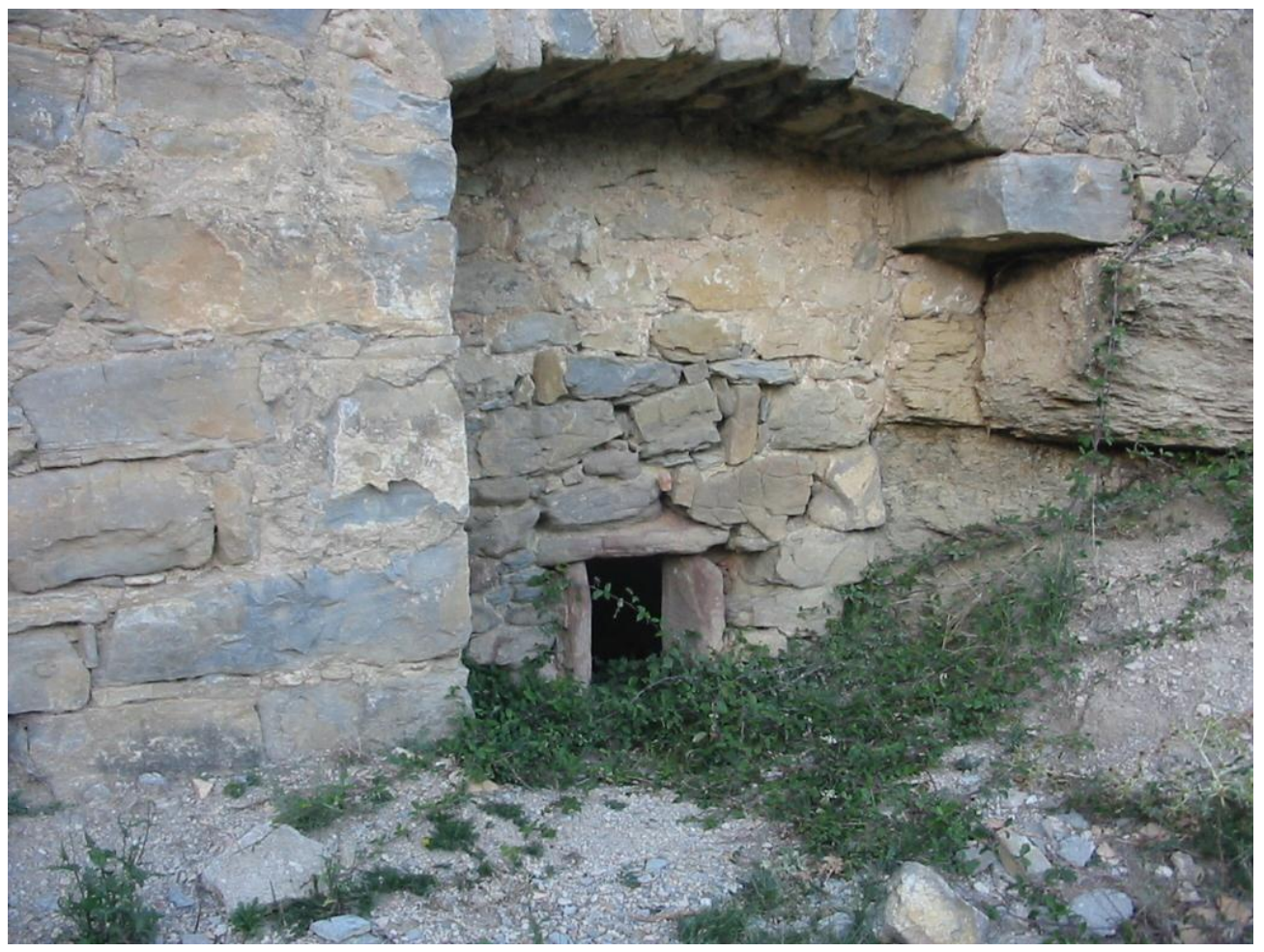

Boca del horno del tejar 
PARADA 4. TERRERAS DE ERIPOL, (Eripol, término municipal de Barcabo, comarca del Sobrarbe). (Hoja 249).

Tras realizar la parada anterior, conviene retornar a la carretera para llegar hasta el pueblo de Almazorre Puede irse directamente hacía el pueblo. También puede regresarse hacía la carretera por el camino de acceso. Luego, desde el pueblo conviene seguir por la carretera hacía el Norte. Así se pasará por el Puerto de Eripol. Luego por las cercanías del pueblo de Eripol. Tras ello, se llegará a un grupo de antiguas explotaciones terrígenas. Ahí haremos una nueva parada, a unos $6-7 \mathrm{Km}$ de la parada anterior.

Como en los casos anteriores, en este recorrido hemos transitado siempre por los afloramientos mesozoicos del Surpirineo Central, en los denominados Pirineos Meridionales, en donde ahora estamos situados.

En este lugar hay varias explotaciones terrígenas, de los derrubios cuaternarios. Estos materiales se han destinado a la construcción del firme de la carretera.

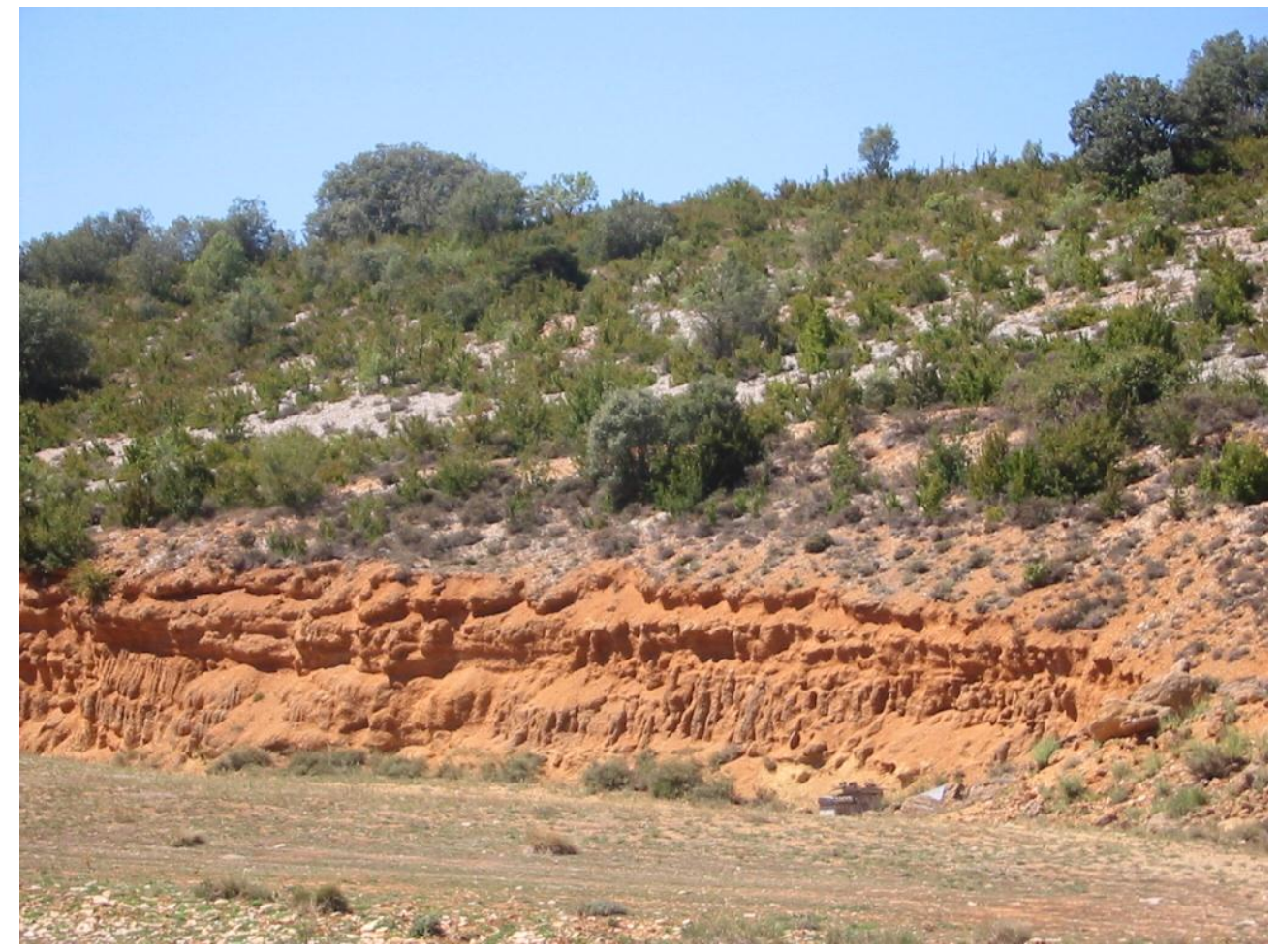

Una de las terreras de Eripol

PARADA 5. TERRERA DE URBIALES, (Urbiales, término municipal de l'Ainsa - Sobrarbe, comarca del Sobrarbe). (Hoja 211).

Después de realizar la parada anterior, es necesario continuar por la carretera que conduce hacía el Norte. Así, pronto se pasará por la población de Arcusa y por las cercanías de Castellazo. Luego, más adelante, se llegará a las inmediaciones de Urdiales (situado a la derecha de la carretera). Poco después se llegará a una explotación terrígena. En este lugar haremos una nueva parada, a unos $8 \mathrm{Km}$ de la anterior. 
Como en los casos anteriores, en los recorridos a las diferentes paradas, también en este recorrido habremos transitado siempre por los afloramientos de los materiales mesozoicos del Surpirineo Central, en los denominados Pirineos Meridionales, en donde ahora estamos situados, desde el inicio del recorrido en Lecina.

Como en el caso de la parada anterior, en este lugar hay una explotación terrígena, de los derrubios de pendiente cuaternarios. Estos materiales se han destinado a la construcción del firme de la carretera.

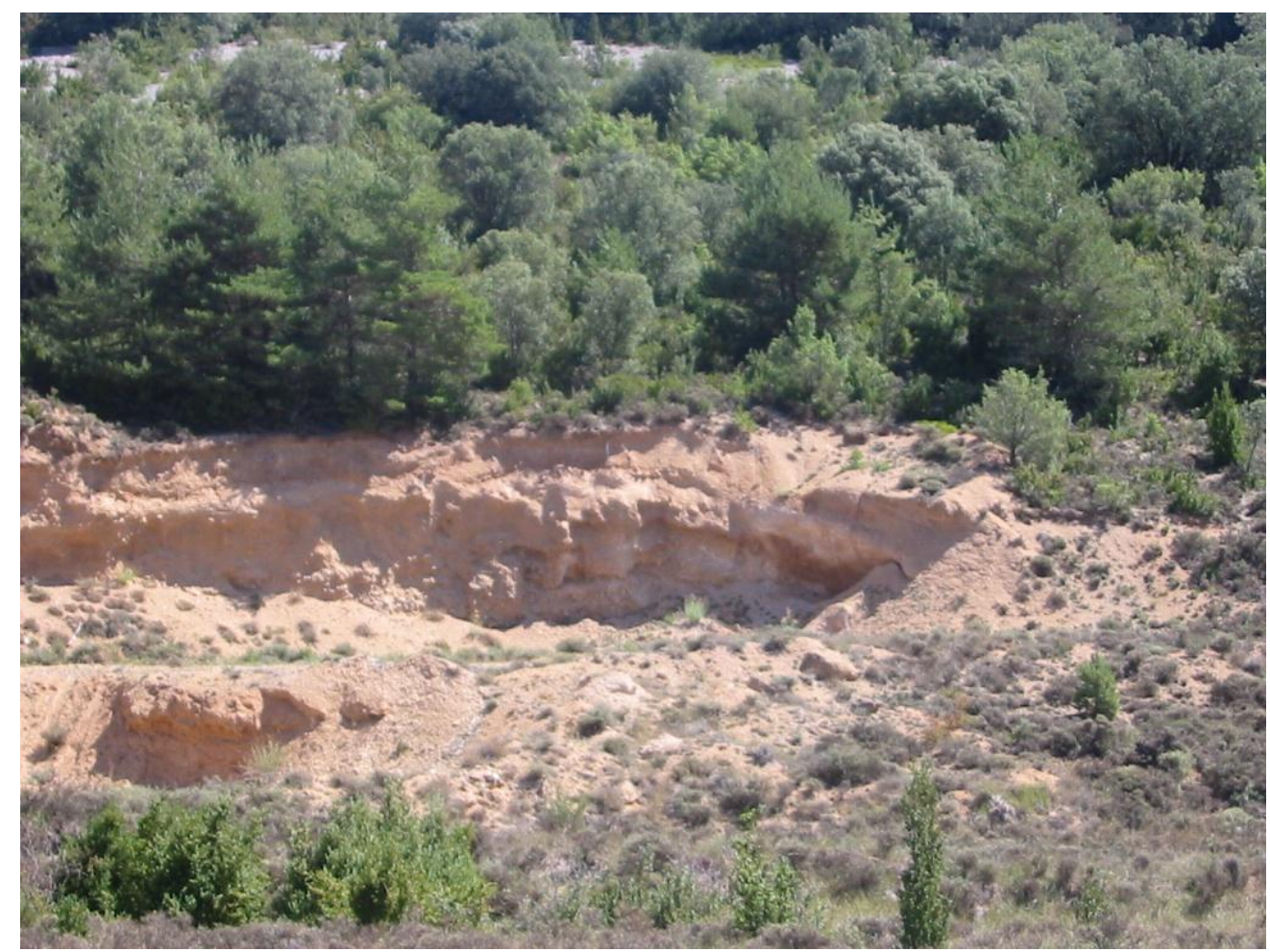

Terrera de Urbiales

PARADA 6. LA TEJERÍA DE BOLTAÑA, (término municipal de Boltaña, comarca del Sobrarbe). (Hoja 211).

Tras realizar la parada anterior, conviene continuar por la carretera que conduce a Boltaña. En este recorrido se pasará por Latorrecilla. Posteriormente se llegará a las inmediaciones del pueblecito de Margudgued. Poco después se llegará a la carretera N260, que nos convendrá tomarla en su sentido hacía Boltaña. Poco después llegaremos a este pueblo, en donde efectuaremos una nueva parada, la última de este recorrido. Ésta la haremos a la entrada de la población. Así, desde la anterior, habremos recorrido unos $10 \mathrm{Km}$ más.

Una vez más, en este recorrido hemos ido encontrando afloramientos de los materiales mesozoicos que forman parte del Surpirineo Central, en los denominados Pirineos Meridionales. Estos materiales los hemos ido encontrando hasta la misma población de Boltaña. 
En este lugar, en donde efectuamos la presente parada, se hallaba una antigua tejería. En ella se aprovechaban unos materiales calcolutíticos extraídos de las cercanías. Por lo que concierne a la tejería, a pesar de hallarse muy transformada, forma parte del Patrimonio Minero del Sobrarbe.

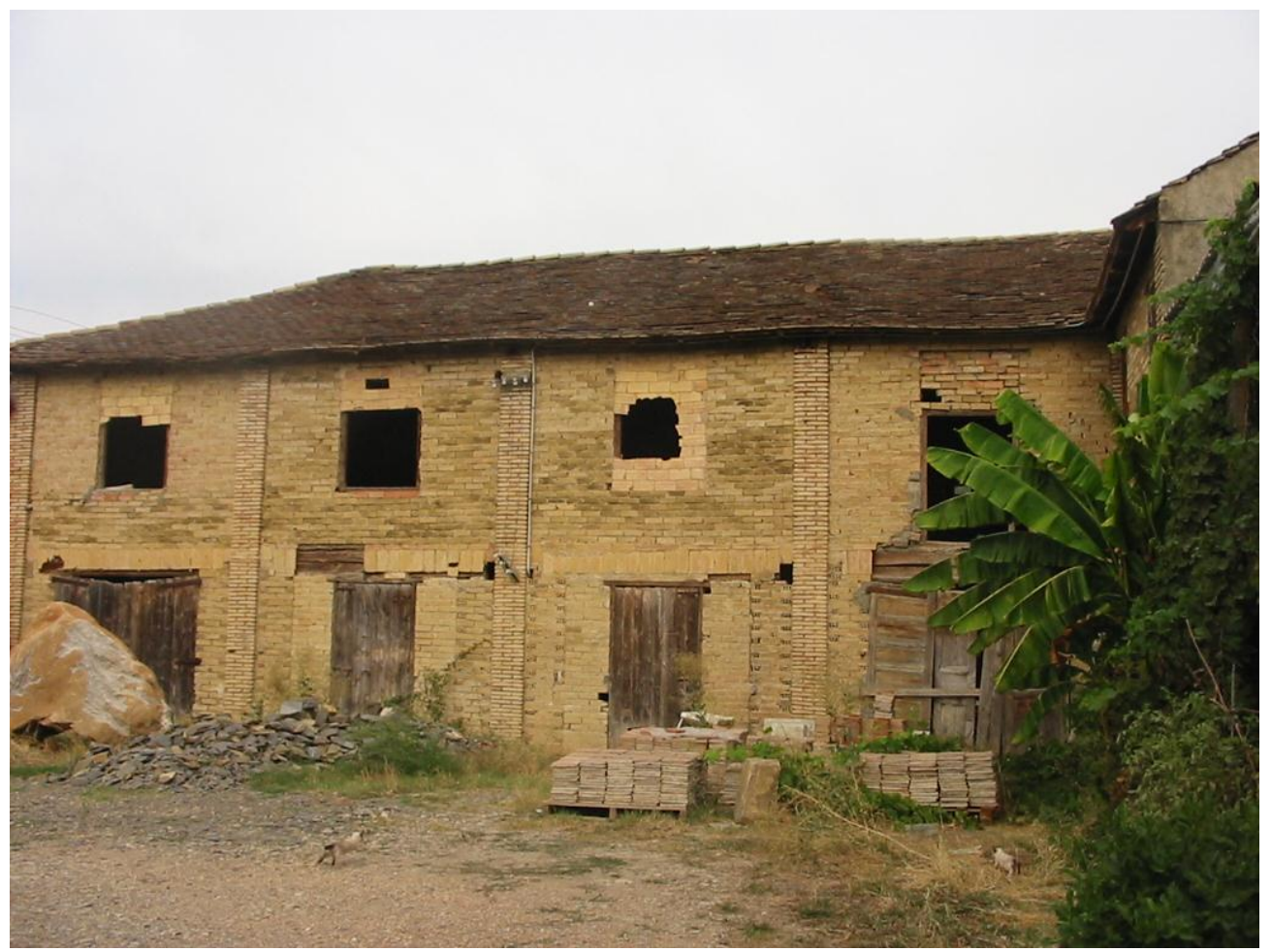

Restos de los edificios de la tejería

EN ESTE LUGAR FINALIZA EL ITINERARIO

\section{BIBLIOGRAFÍA}

CALVO, M. et altri (1988). - Minerales de Aragón, Colección Temas Geológicos, 207 Pág. Zaragoza 


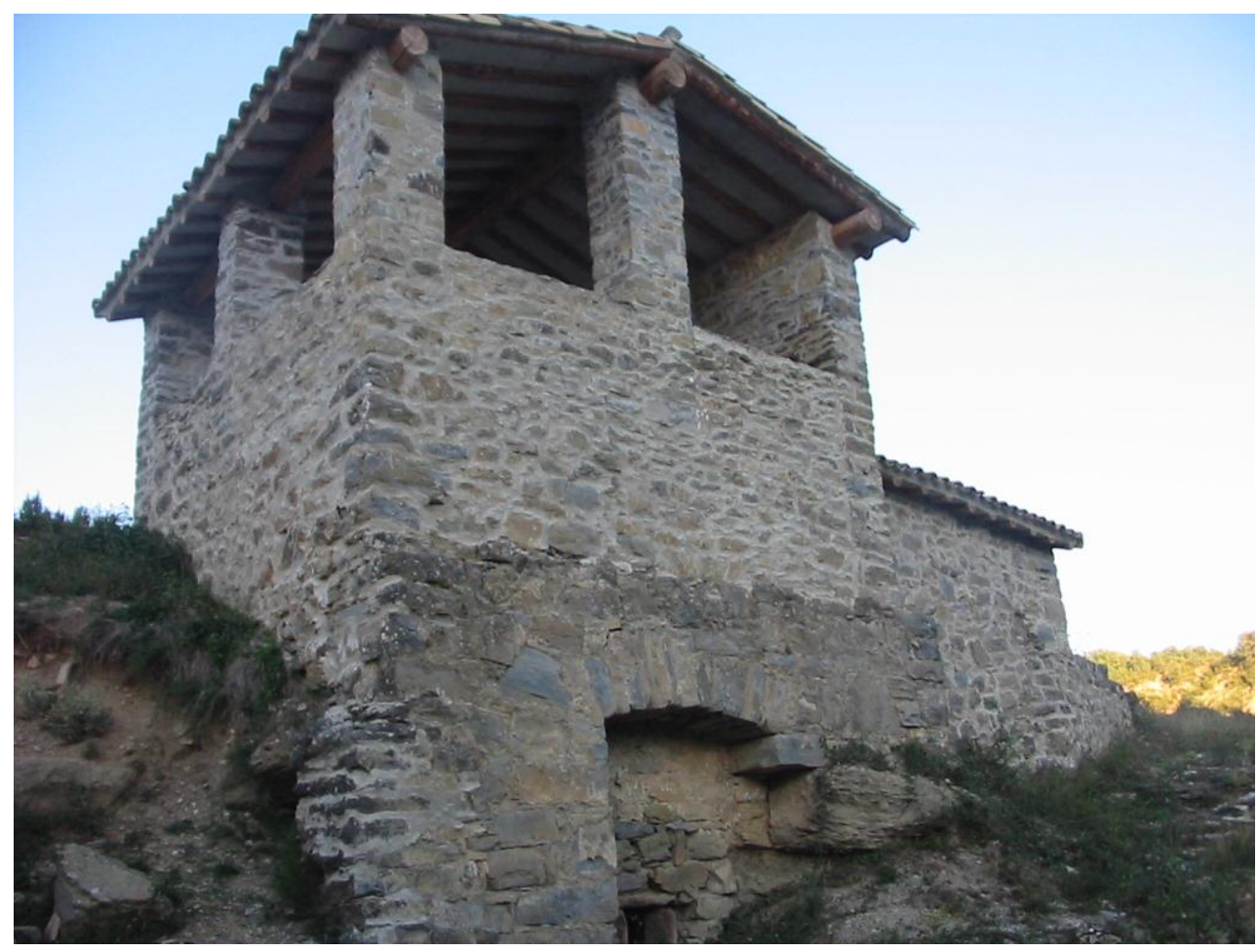

EL TEJAR DE ALMAZORRE (BARCABO)

GOBIERNO DE ARAGÓN (2001).- Puntos de Interés Geológico de Aragón. Consejería de Medio Ambiente del Gobierno de Aragón. Zaragoza

IGME (1972).- Mapa Geológico de España a escala 1:200.000 (Síntesis de la cartografía existente). Hoja y Memoria na 23 (Huesca). Inst. Geol. Min. España

IGME (1973).- Mapa Metalogenético de España a escala 1:200.000. Hoja y Memoria ${ }^{\mathrm{a}}$. 23 (Huesca). Inst. Geol. Min. España

IGME (1975).- Mapa de Rocas Industriales de España a escala 1:200.000. Hoja y Memoria $n^{a} .23$ (Huesca). Inst. Geol. Min. España

MAESTRE, A. (1845).- Descripción geognóstica del Distrito Minero de Cataluña y Aragón. Anales de Minas, t. III. Madrid

MATA - PERELLÓ, J.; (1987).- Introducción al conocimiento de las mineralizaciones aragonesas. Mineralogistes de Catalunya, t.III, pp. 258-265. Barcelona

MATA - PERELLÓ, J.M. (1992).- Inventario Mineralógico de la comarca del Sobrarbe. Rodeno, 13. 42 Pág. Manresa

MATA - PERELLÓ, J.M. y SANZ-BALAGUË, J. (1992).- Guía de Identificación de Minerales, adaptada fundamentalmente a la Península Ibérica. Edic. Parcir, 243 pag. Manresa 
PRAMES (2005).- Sobrarbe. Colección RUTASCAL por Aragón. Prames, Gobierno de Aragón. 119 pag. Zaragoza. 